\title{
DERECHO, MORAL Y LEYES INMORALES
}

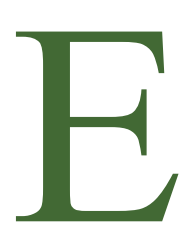

1 artículo comenta el clásico debate mantenido por Hart y Fuller desde 1950, el trabajo de Robert Alexy «On Necessary connection between Law and Morality» y el de Aleksander Peczenik «Weighing Rights» junto a su último libro On Law and Reason.

Hart basó su teoría del Derecho en la tradición del positivismo jurídico y especialmente en la teoría del mandato tal como es formulada por John Austin. Hart adoptó la idea de Austin de la separación estricta entre el «Derecho que es» y el «Derecho que debe ser», si bien Kelsen también ha tenido una enorme influencia en el concepto de Derecho de Hart.

La piedra angular de la teoría de Hart es la noción de regla de reconocimiento, próxima a la Grundnorm de Kelsen, pero que a diferencia de la norma fundamental de Kelsen está des provista de contenido normativo, pues la norma de reconocimiento de Hart tiene una textura abierta y es puramente formal. El sistema jurídico es indiferente respecto a los valores en tanto no transgrede la noción de Hart del contenido mínimo de Derecho natural. Hart argumenta, en este sentido, que la distinción conceptual ser/deber ser en el Derecho posibilita la crítica de los contenidos materiales de un sistema jurídico con mayor fuerza argumentativa y crítica que la concepción de Fuller (i.e. el argumento de Hart «esto es Derecho, pero demasiado inicuo para ser obedecido o aplicado).

En este trabajo sugiero la idea de que la regla de reconocimiento de Hart puede tener una lectura semiótica, en cuanto no provee de forma inmediata o primaria (ex ante) criterios para el reconocimiento de las normas jurídicas válidas, sino más bien el seguimiento de la práctica de los tribunales (ex post facto). En términos semióticos puede decirse que la regla de reconocimiento de Hart admite diversos tipos de discursos jurídicos y no se adhiere a la «ontología platónica» del Derecho, en la terminología de Bernard S. Jackson. Entiendo que el contenido mínimo 
del Derecho natural de Hart puede ser analizado como conjunto de normas técnicas según la estructura «si... entonces», dirigido al legislador: si deseas hacer un Derecho eficiente, debes respetar estas normas técnicas sin las que el sistema jurídico perdería su funcionalidad.

Lon L. Fuller argumenta, a este respecto, con lo que denomina la «moral interna del Derecho», que consiste en ocho «principios de legalidad». Fuller sostiene que un sistema jurídico que no tenga en cuenta estas reglas inherentes para orientar la legislación, perderá su validez jurídica. sin embargo, con la única excepción del requisito de la promulgación, Fuller se encuentra obligado a interpretar la moral interna del Derecho en términos únicamente de moral de aspiración y no de moral de deber. De modo que los siete requisitos restantes son reducidos a exigencias de «legalidad perfecta»y al «orgullo de su artífice». Hart analiza los principios de legalidad de Fuller como normas técnicas, como requisitos de un sistema jurídico eficiente y que no tiene con la moral más relación que, como señala Hart en su sarcástico ejemplo, la «moral del envenenamiento». Hart etiqueta la idea de Fuller como absurda pues una violación, por ejemplo, del requisito de la no retroactividad en Derecho Penal no significaría más que un defecto o un incumplimiento de la moral de aspiración. Sin embargo, el propio esquema conceptual de Hart lleva a un resultado final bastante similar, es decir, al argumento «esto es Derecho, pero mal Derecho».

Robert Alexy sostiene una relación conceptual entre Derecho y moral que arranca de la pretensión de corrección inherente al Derecho. De acuerdo con el ejemplo de Alexy, un artículo en la constitución de un Estado ficticio que dijera «X es un Estado soberano, federal e injusto» incluye una contradicción performativa y por tanto es jurídica y conceptualmente imperfecto. Un defecto conceptual al nivel del sistema jurídico en su conjunto conduce a la total invalidez del sistema jurídico, dado que la relación entre Derecho y moral es de orden definitorio; mientras que un defecto conceptual en el nivel de una norma jurídica individual o una decisión jurídica sólo llevaría a que la norma o la decisión fueran «imperfectas» o «mal» Derecho, dado que la relación entre Derecho y moral es de carácter cualificatorio. En este sentido la tesis de Alexy está muy cercana a la idea de la moral interna del Derecho como parte de la moral de aspiración de Fuller. En este análisis me referiré a la tesis de Alexy sobre el defecto conceptual en una constitución ficticia como tesis referida al sistema jurídico en su conjunto y no únicamente a una norma individual, pues los artículos básicos de la constitución 
constituyen el marco del resto de piezas de la legislación de un Estado.

El ejemplo de Alexy está relacionado con la idea de Habermas de pragmática universal. Los enunciados constatativos que se contradicen a sí mismos como el ejemplo de Austin «el gato está en el felpudo pero yo no lo creo» sin duda no tienen sentido lógicamente, y la argumentación no puede ser utilizada analógicamente en el caso de enunciados prácticos o regulativos. Los enunciados prácticos chocantes pueden ser también, en terminología de Austin, enunciados «desafortunados», pero no son lógicamente sin sentido, como argumentaré en este texto. Brevemente comentaré otro buen ejemplo de Alexy, extraído de un veredicto de un juez ficticio: «El demandado es -injustamente porque el Derecho válido fue interpretado incorrectamente- sentenciado a cadena perpetua.» Este supuesto difiere del mencionado con anterioridad, pues lo que está en juego no es la injusticia de un aspecto de la legislación, sino una interpretación del Derecho abiertamente contra legem. Sin embargo, en el caso de una decisión jurídica particular el defecto conceptual sólo puede tener un carácter cualificatorio, como el propio Alexy señala, de forma que la situación es igual a la consideración de Fuller de «menos que perfecto» o a un mal aspecto de la jurisdicción y nada más.

Finalmente comentaré el artículo de Aleksander Peczenik «Weighing Rights», donde argumenta en favor de un vínculo conceptual entre Derecho y moral. Peczenik formula la distinción entre una moral prima facie o deber jurídico y un deber jurídico o moral del tipo consideradas-todas-las-circunstancias. Peczenik sostiene que un deber jurídico prima facie significa un deber moral prima facie también y que el mismo enunciado puede hacerse con referencia a la relación entre un deber jurídico consideradas-todas-las-circunstancias y el correspondiente deber moral. Sólo en el caso de un sistema jurídico «sistemáticamente inmoral», inmoralidad en la que deberíamos comprender también las «disposiciones técnicas de Derecho civil», se podría negar su carácter de orden jurídico. Como señala Peczenik, «una disposición inmoral o un aspecto sistemáticamente inmoral del sistema no es suficiente». Una disposición inmoral individual del Derecho podría y debería ser interpretada de un modo restrictivo o ignorar la disposición junto con el procedimiento jurídico de contrapeso y ponderación.

En la concepción del Derecho de Peczenik incluso el régimen nazi no sería suficientemente inmoral y, de este modo disfrutaría del status de un sistema jurídico obligatorio prima facie, pues la 
inmoralidad no comprendería el sistema jurídico en su conjunto sino que dejaría intactos, p. ej. amplios sectores del BGB (Código civil alemán). Aunque acepto la perspectiva básicamente hobbesiana de Peczenik respecto a la naturaleza humana y la sociedad, critico sin embargo su idea de que la existencia de un deber jurídico consideradas-todas-las-circunstancias signifique la existencia de un deber moral correspondiente que obligue con el mismo contenido. Encuentro en la tesis de la inclusión de Peczenik sólo un enunciado analítico, pues el procedimiento de interpretación jurídica de Peczenik (contrapeso y ponderación) comprende necesariamente también valoraciones morales, sin las cuales la interpretación perdería su carácter jurídico en la teoría de Peczenik. En otros términos, los valores están siempre presentes como parte integrante del procedimiento de interpretación, y es por ello por lo que al final el resultado de la interpretación tiene también un componente moral.

\section{HART VERSUS FULLER: LOS TRES ASALTOS}

El antecedente intelectual del clásico debate entre H. L. A. Hart y Lon L. Fuller se encuentra en las clases de Dritte Reich sobre jurisdicción en Alemania, bajo el régimen nazi. Los nazis habían transformado la noble tradición jurídica alemana en una cruel e inhumana parodia del Estado de Derecho. Tras la guerra, Gustav Radbruch ${ }^{1}$, uno de los filósofos del derecho más importantes de Alemania, se sintió impelido a repensar su teoría positivista del Derecho de la preguerra y llegó a una concepción que se adhería al Derecho natural. La conversión de Radbruch parece simbolizar la situación de la teoría del Derecho en general de la posguerra. Unos diez años después, Hart y Fuller tomaron en consideración de nuevo este ensayo.

El primer asalto del debate apareció en 1958 en Harvard Law Review. «Positivism and the Separation of Law and Morals» ${ }^{2}$ de Hart abrió la discusión y Fuller respondió con su artículo «Positivism and Fidelity to Law. A Reply to Professor Hart» ${ }^{3}$. Hart

1 Vid. «Fünf Minuten Rechtsphilosophie» (1945) y «Gesetzliches Unrecht und übergesetzliches Recht» (1946), en G. Radbruch, Rechtsphilosophie, K. F. Koeffier Verlag, 1973, págs. 327 y sigs., $339 \mathrm{y}$ sigs.

271 Harvard Law Review, págs. 593 y sigs.; en lo que sigue me referiré a su reimpresión en The Philosophy of Law, J. Feinberg, y H. Gross eds., Wadsworth 1980 (2. $\left.{ }^{\text {}}\right)$, págs. 49 y sigs.

${ }^{3} 71$ Harvard Law Review, págs. 630 y sigs. The Philosophy of Law, J. Feinberg, y H. Gross eds. Wadsworth, $1980\left(2 .^{a}\right)$, págs. 68 y sigs. 
presentó y desarrolló su denominada tesis de la separación, que sostenía una separación estricta (kelseniana) del Derecho con respecto a consideraciones morales cualquiera que fuera su contenido. Fuller criticó duramente el positivismo de Hart como incapaz de condenar la posibilidad de un sistema jurídico enormemente injusto. La propia concepción de Fuller se basó en la «moral interna del Derecho». Si Hart funda su teoría en Kelsen, la argumentación de Fuller parece más bien seguir el principio lex iniusta non est lex tal como es presentado, por ejemplo, por Tomás de Aquino o Aristóteles.

El segundo asalto del debate tomó forma en dos libros: The Concept of Law de Hart, publicado en 1961, y The Morality of Law, de Fuller, en 1964. En The Concept of Law, Hart presenta una teoría del positivismo jurídico totalmente desarrollada, modificando la concepción austiniana de «órdenes respaldadas por amenazas» y el normativismo kelseniano basado en la sanción con las nociones de regla de reconocimiento y del «contenido mínimo de Derecho natural», ambos formulados por el propio Hart. La discusión con Fuller continuó fundamentalmente en la sección del libro relativa a «Derecho y moral». Fuller respondió con su formulación más acabada de la «moralidad interna del Derecho» ahora especificada en ocho requisitos internos que todo sistema jurídico ha de satisfacer para ser calificado propiamente como Derecho.

El tercer asalto consistió en la recensión de Hart de Morality of Law, de Fuller, junto a la réplica de Fuller a la crítica en la segunda edición del libro en 1969. En su dura y, en parte, sarcástica revisión, Hart compara los requisitos morales internos del Derecho con «la moral del envenenamiento», lo que implica que los principios de legalidad de Fuller no son más que normas técnicas, desprovistas de consideraciones morales de cualquier contenido. Fuller se adhirió a su noción original, presentando nuevos argumentos a la acalorada discusión. La disputa finalizó y parece que, con el tiempo, los contendientes han acabado con su potencial crítico y argumentativo.

Juzgando desde la retórica acalorada del debate, parecería como si los desacuerdos entre Hart y Fuller no fueran sino irreconciliables. Sin embargo, si ignoramos la retórica y nos centramos en los resultados finales la situación parece bastante diferente. Al juzgar el terror nazi, de hecho, los dos recomiendan

${ }^{4} 78$ Harvard Law Review, 1965, págs. 1281 y sigs. En adelante cito por H. L. A. Hart, Essays in Jurisprudence and Philosophy, Clarendon Press, Oxford, 1983, págs. 343 y sigs. 
-a falta de una alternativa mejor- la legislación penal retroactiva ${ }^{5}$. Sin duda los argumentos difieren: Hart analizó la situación como aquella en la que se enfrentaban dos males (i.e. permitir que los mezquinos delatores y los jueces que aplicaron el Derecho nazi quedaran impunes o hacer uso de la legislación retroactiva) para elegir el mal menor; mientras Fuller argumentó en favor de una ruptura nítida y simbólica con los males del pasado y en favor de un nuevo aspecto de la legislación que serviría para el mejor final.

En este artículo quisiera estudiar los criterios propuestos por Hart y Fuller sobre la exigencia de la relación necesaria entre derecho y moral. No seguiré estrictamente la cronología del debate, sino que haré uso de los que en mi opinión son los argumentos más importantes y más elaborados por cada parte. Junto al mencionado texto, me referiré a otros dos, a la provocadora aunque problemática lectura de «On Necessary Relations between Law and Morality», de Robert Alexy, sostenida en el Murikka Symposium (en Finlandia) en 1988 y publicado en Ratio Juris, 1989, 2 y la lectura de «Weighing Rights», de Aleksander Peczenik, que tuvo lugar en el Congreso de Edimburgo en $1989^{6}$, junto a su último libro Law and Reason ${ }^{7}$.

\section{H. L. A. HART Y LA RELACIÓN ENTRE DERECHO Y MORAL}

\subsection{De las órdenes del asaltante ala regla de reconocimiento}

La tesis de la separación de Hart sostiene que no existe una conexión necesaria entre el derecho y la moralidad o entre el Derecho que es y el que debe ser. La tesis de la separación está estrechamente relacionada con la distinción de Hume ser/deber

${ }^{5}$ H. L. A. Hart, «Positivism and the separation of Law and Morals», art. cit., pág. 60; Hart, The concept of Law, cit., pág. 202; L. L. Fuller, «Positivism and Fidelity to Law. A Reply to Professor Hart», art. cit., pág. 82. Según he podido detectar, los contendientes no alteraron sus posiciones en este punto en las últimas fases de la discusión.

${ }^{6}$ El trabajo de Robert Alexy se publicó en Ratio Juris, 2/1989, págs. 167-183, y el de Aleksander Peczenik se publicó en Enlightenment, Rights and Revolution. Essays in Legal and Social Philosophy, N. MacCormik y Z. Bankowski eds., Aberdeen University Press, 1989, págs. 175-196.

${ }^{7}$ Kluwer Academic Publishers, Law \& Philosophy series, núm. 8, Netherlands, 1989. 
ser (Sein/Sollen $)^{8}$. Hart se refiere a Austin de comienzos del siglo XIX: «La existencia del Derecho es una cosa, su mérito o demérito es otra.» En la base de la concepción de Hart se encuentra la idea de Kelsen de un Derecho «purificado» (Reine Rechtslehre): ningún material extrajurídico debería mezclarse con el Derecho como es. Junto a ello, el análisis de las modalidades jurídicas de Wesley Newcomb Hohfeld ha tenido una enorme influencia en la teoría jurídica de Hart".

En la teoría de John Austin, el Derecho consiste en «órdenes respaldadas por amenazas», órdenes coercitivas promulgadas por el soberano y respaldadas por la amenaza de la sanción. El poderoso soberano mantiene un estrecho parecido con la descripción agustiniana del Estado como magna latrocinia, o banda de ladrones. Hart plantea la cuestión de cuál es la diferencia entre un ladrón que apunta a un oficinista de un banco con una pistola y dice: «iSu dinero o su vida!» y, de otro lado, un legislador que también emite órdenes respaldadas por amenazas de fuerza. En el análisis de Hart la tesis de Austin es insostenible para formular el tipo de distinción que habría entre la situación del robo de un banco y un sistema jurídico. Pues lo que falta es el concepto de regla general, que obligaría al ladrón y a la víctima con igual fuerza. Hart concluye desde su análisis lingüístico que «tener una obligación» caracteriza la existencia de una regla general (jurídica), mientras la expresión «estar obligado a» puede restringirse sólo a la concreta situación del robo del banco.

Junto a las reglas generales obligatorias, que pueden ejemplificarse bien con las reglas de Derecho penal, el sistema jurídico comprende reglas que confieren potestades: reglas de cambio, de adjudicación, más la regla básica de reconocimiento. La existencia de un sistema jurídico tiene dos requisitos en la teoría de Hart:

«Existen, por tanto, dos condiciones mínimas necesarias y suficientes para la existencia de un sistema jurídico. Por un lado, las reglas de conducta que son válidas de acuerdo con los criterios últimos de validez del sistema deben ser generalmente obedecidas $\mathrm{y}$, de otro lado, sus reglas de reconocimiento especifican los criterios de validez y sus reglas de cambio y adjudicación

${ }^{8}$ Con relación a la dicotomía ser/deber ser, puede verse, por ejemplo, la voz «être/deboir être», en el Dictionnaire encyclopédique de théorie et de sociologie du droit, dirigido por A. J. Arnaud. E. Story Sciencia, Bruxelles, 1988.

${ }^{9}$ Sobre la relación de Hart con respecto a Hohfeld puede verse el comentario de Fuller en Morality and Law, nota 50, pág. 134, y The Concept of Law, de Hart, págs. 77 y sigs. 
deben ser efectivamente aceptadas por sus operadores jurídicos como standards públicos y comunes de comportamiento oficial ${ }^{10}$.

En la teoría de Hart la regla de reconocimiento juega un importante papel. Constituye el criterio último con respecto al cual ciertas normas son reconocidas como legalmente válidas por los jueces y otras autoridades. La regla de reconocimiento es parecida a la Grundnorm de Kelsen ${ }^{11}$, pero a diferencia de la norma fundamental de Kelsen aquélla carece de fuerza normativa. Sólo existe «como una práctica compleja, pero normalmente concordante, de los tribunales, funcionarios y particulares, al identificar el Derecho por referencia a ciertos criterios. Su existencia es una cuestión de hecho» ${ }^{12}$. Por otra parte, la regla de reconocimiento tiene una textura abierta. Puede ser formulada, por ejemplo, como «lo que la reina promulga en el Parlamento es Derecho (en Inglaterra)», pero usando una definición más amplia comprende todas las fuentes del derecho reconocidas como válidas en un sistema jurídico: constitución, legislación escrita, precedentes, trabajos preparatorios, etc..$^{13} \mathrm{El}$ contenido material de la regla de reconocimiento varía de acuerdo con los cambios en la doctrina dominante de las fuentes de Derecho. La regla de reconocimiento sigue los cauces de la praxis aplicativa del Derecho, siendo igual a: el Derecho es lo que es realizado como Derecho por los jueces, otros operadores jurídicos, y los ciudadanos.

Hart sitúa la regla de cambio (normas sobre elaboración de leyes, contratos, testamentos, etc.) y las reglas de adjudicación (normas de procedimiento) al mismo nivel que la regla de reconocimiento, lo que en mi opinión es incorrecto. Pues las reglas de cambio y adjudicación necesitan ser identificadas también utilizando la regla de reconocimiento como criterio de validez, esta última tiene que tener por tanto un elevado nivel de abstracción. Por consiguiente, su caracterización seria mejor más bien como una norma trascendental (en sentido kantiano), pues la regla fundamental de Hart recibe sus límites externos de la praxis jurídica y no viceversa. Si los tribunales de un determinado sistema jurídico deciden que desde ahora los derechos humanos básicos

${ }^{10}$ H. L. A. Hart, The Concept of Law, cit., pág. 113

${ }^{11}$ El propio Hart establece una comparación entre la Grundnorm de Kelsen y la regla de reconocimiento en The Concept of Law, cit. página 97 y página 245.

${ }^{12}$ H. L. A. Hart, The Concept of Law, cit., pág. 107.

${ }^{13}$ Ibid., pág. 98. 
serán tomados como fuente material jurídicamente obligatoria (lo que no es el caso actual en Finlandia), de modo que la propia regla de reconocimiento se ajustará a la situación modificada y no al revés. Afirmar que la regla de reconocimiento sirve como criterio sería erróneo en este caso, pues la regla fundamental de Hart sólo sigue el cambio en la praxis jurídica (y la situación es similar en el caso de otros operadores jurídicos). Por supuesto, la tradición jurídica tiende a «congelar» el conjunto de fuentes jurídicas reconocidas según un criterio oficialmente aceptado y, de este modo, la regla de reconocimiento es capaz de servir como guía también para los jueces. Sin embargo, todavía se podría argumentar que la praxis judicial mantiene la posición más importante con respecto a la regla de reconocimiento está desprovista de cualquier contenido normativo, su existencia es, en palabras de Hart, «una cuestión de hecho empírica aunque compleja» ${ }^{14}$.

De hecho, la explicación de Hart de la textura abierta de la regla de reconocimiento y el correspondiente perfil de la esfera del Derecho se encuentra cercana a las ideas propuestas por la orientación estructuralista de la semiótica (gremasiana) al Derecho, existe un «Derecho» no coherente o un «sistema jurídico» en algún lugar «más allá», según la concepción platónica del mundo. En lugar de ello, el discurso jurídico consiste en textos que por sí mismos exigen ser considerados jurídicamente y la exigencia de validez jurídica es una parte del mensaje del texto y no una referencia a una realidad extrajurídica. Y ésta es exactamente la función que Hart atribuye a la regla de reconocimiento: definir los límites «del» Derecho de acuerdo con los standards utilizados por los discursos legislativo, judicial y privado. Hart evita claramente la trampa de la «ontología platónica» en la que cae la teoría institucional del Derecho de Neil MacCormik, como ha argumentado convincentemente Bernard S. Jackson ${ }^{15}$.

\subsection{El contenido mínimo de Derecho natural}

Hasta cierto punto, el contenido material del sistema jurídico

${ }^{14}$ H. L. A. Hart, op. cit., pág. 107 y esp. 97 y 245. Hart continúa más adelante en la nota a pie de página, donde compara la regla de reconocimiento con la Grundnorm de Kelsen: «Si se lo contro vertiera, lo que queda así presupuesto pero no expresado podría ser establecido recurriendo a los hechos, esto es, a la práctica efectiva de los tribunales y funcionarios del sistema al identificar el derecho que han de aplicar.» Ibid.

${ }^{15}$ Vid. B. S. Jackson, Semiotics and Legal Theory, Routledge \& Kegan Paul, London, 1985, págs. $175 \mathrm{y}$ sigs. 
puede comprender cualquier cosa en la teoría de Hart. En orden a evitar la posibilidad de un régimen jurídico altamente injusto como el nazi, Hart ha de introducir el contenido mínimo de Derecho natural ${ }^{16}$ la única restricción que Hart impone al legislador. Dado que la sociedad humana no es un «club de suicidas», existen determinados requisitos -no necesariamente inherentes- que todo sistema jurídico ha de satisfacer si quiere contar con la obediencia de los ciudadanos. Si falta el respeto por tales requisitos básicos, que conciernen, por ejemplo, a un respeto mínimo a la vida humana, propiedad y al cumplimiento de las promesas no habría lugar a la obediencia voluntaria de otras reglas de cualquier contenido. Dado que ningún sistema jurídico puede funcionar sin un mínimo de cooperación voluntaria de sus sujetos, tal sistema jurídico perdería su efectividad ${ }^{17}$. El contenido mínimo de Derecho natural, concluye Hart, comprende «el núcleo del buen sentido de la doctrina del Derecho natural».

Sin embargo, la noción de Derecho natural de Hart está desprovista de cualquier tipo de validez normativa: los principios de este manifiesto de Derecho natural minimalista parecen ser meramente de carácter contingente, basados en las observaciones generales de la naturaleza humana («si los seres humanos tuvieran esferas naturalmente protegidas para cubrirlos efectivamente y hacerlos invulnerables frente a los ataques de otros, entonces no habría lugar a la prohibición del homicidio»). Además, las reglas de Derecho natural de Hart pueden ser interpretadas mejor como conjunto de reglas técnicas, dadas al legislador: si quieres promulgar un sistema jurídico que funcione, estas son las reglas que hay que observar. El carácter relativamente contingente y técnico «si... entonces» de las leyes naturales de Hart lo separa de la propia tradición del Derecho natural, con la cual claramente se les da fuerza normativa. Para Hart las leyes son una «necesidad natural» que guía un esfuerzo de producción normativa del que cabe que espera que sea eficiente porque «su verdad depende de que los seres humanos y el mundo en que viven conserven las características sobresalientes que hoy tienen $\rangle^{18}$.

Hart ve los principios de legalidad de Fuller sólo como conjunto de normas técnicas que orientan la efectividad y buen funcionamiento de los proyectos de ley, desprovistos de cualquier contenido moral ${ }^{19}$. Hart argumenta que el propósito de la acción

${ }^{16}$ H. L. A. Hart, The Concept of Law, cit. págs. 189 y sigs.

${ }^{17}$ Ibid., pág. 196.

${ }^{18}$ Ibid., pág. 195.

${ }^{19}$ Ibid., pág. 202. 
humana no tiene nada que ver con su moralidad interna, y toma «la moral del envenenamiento» como un contraejemplo sarcástico para competir con el que presenta Fuller $^{20}$.

\section{LON L. FULLER Y «LA MORAL INTERNA DEL DERECHO»}

Aunque The morality of Law de Fuller no se refiere explícitamente a la teoría del Derecho de Rudolf von Ihering, la idea de Der Zweck im Recht bien podría servir como lema del libro de su totalidad ${ }^{21}$. Fuller tiene una firme convicción en la intencionalidad en el Derecho, por consiguiente la tarea de la elaboración de las leyes no puede reducirse a una mera tecnología social (positivista) de tipo hartiano. El Derecho es una actividad humana de carácter final y como tal se orienta por unas reglas inherentes y moralmente obligatorias situadas más allá del legislador.

Lon L. Fuller critica la teoría positivista del Derecho de Hart por cuanto no toma en cuenta lo que denomina la «moral interna del Derecho», la «moral que hace posible el Derecho» o los principios de legalidad. De acuerdo con Fuller, la moralidad interna del Derecho consiste en los siguientes requisitos: las reglas deberían ser 1) generales; 2) dadas a conocer o disponibles para afectar a las partes (promulgación); 3) prospectivas, no retroactivas; 4) claras y comprensibles; 5) sin contradicciones; las reglas no deberían 6) exigir lo que es imposible; 7) ser cambiadas frecuentemente y finalmente, 8) deberían haber una congruencia entre el Derecho y la acción oficial ${ }^{22}$.

Fuller argumenta:

«Una falta absoluta de alguno de estos ocho requisitos no sólo da como resultado un mal sistema jurídico; da lugar a algo que no puede calificarse propiamente como sistema jurídico, excepto en sentido de Pickwick, según el cual un contrato nulo todavía puede considerarse como un tipo de contrato $\rangle^{23}$.

Sin embargo, pocas páginas después Fuller ha de admitir que -con la sola excepción de la promulgación de las leyes- la

${ }^{20}$ H. L. A. Hart, Essays in Jurisprudence and Philosophy, cit. pág. 350.

${ }^{21}$ Vid., por ejemplo, el capítulo «The Substantive Aims of Law», The Morality of Law, cit. págs. 152 y sigs., «Law as a Purposeful Enterprise and Law as a Manifested Fact of Social Power», op. cit., págs. 145-151.

${ }^{22}$ L. L. Fuller, The Morality of Law, cit. pág. 39. Hart, Essays in Jurisprudence and Philosphy, cit., pág. 347.

${ }^{23}$ L. L. Fuller, The Morality of Law, cit. pág. 39. 
moral interna del Derecho sólo tiene el status de una moral de aspiración, no de una moral del deber, y su principal exigencia debe ser encontrada en el «orgullo de su artífice» ${ }^{24}$. Lo que Fuller quiere expresar con esta noción no está enteramente claro. Una ruptura en la moral interna del Derecho de Fuller, después de todo, no desprovee al Derecho de su validez sino sólo da lugar a un «mal» Derecho. Sólo si el legislador comete un error en la promulgación de las leyes viola propiamente la moral del deber, y es sólo entonces cuando el Derecho pierde su validez y deja de ser Derecho. Si el requisito de la promulgación no es violado el resultado puede ser algo que no alcanza al «orgullo de su artíficeano» o un Derecho perfectamente bien estatuido, pero, en cualquier caso, es un Derecho válido. Los siete requisitos restantes no son más que medios para la «legalidad perfecta»o «perfección en la legalidad $»^{25}$.

En contraposición, la moral externa del Derecho comprendería los valores en los que un sistema jurídico se apoya y protege, pero no son objeto de atención ni por parte de Fuller ni de Hart en este momento.

Por otra parte, Fuller piensa que los principios de legalidad no son indiferentes a los contenidos materiales del Derecho. En su opinión, los fines inhumanos del régimen nazi no podrían haber sido perseguidos con una «legalidad perfecta», esto es, siguiendo los principios de legalidad. Fuller escribe:

«Habré de mantenerme en la afirmación de una convicción que puede parecer ingenua, a saber, que la coherencia y la maldad. Aceptada esta convicción, creo también que cuando los hombres se encuentran obligados a explicar y justificar sus decisiones, el efecto será, en general, orientar aquellas decisiones hacia la bondad cualquiera que sean los modelos últimos de bondad» ${ }^{26}$.

Hart criticó duramente esta concepción. ¿Por qué deberían relacionarse las características formales del Derecho con sus contenidos materiales? ¿Es in casu la jurisdicción de la equity, necesariamente material, peor que la coherente pero inhumana aplicación de un Derecho nazi debidamente estatuido? ¿Está justificada la consideración global de Fuller de la moral interna del Derecho?

En el debate, Hart acusó a Fuller de confundir moralidad y

${ }^{24}$ Ibid., pág. 43.

${ }^{25}$ Ibid., pág. 41.

${ }^{26}$ L. L. Fuller, «Positivism and Fidelity to Law. A Replay to Professor Hart», art. cit., pág. 71. 
efectividad del Derecho. En The Concept of Law, Hart todavía adoptó una aproximación parcialmente aprobatoria respecto de la teoría de Fuller, aun cuando afirmara que «desgraciadamente» (la conexión necesaria entre Derecho y moral) es incompatible con una gran iniquidad ${ }^{27}$. En su recensión de The Morality of Law de Fuller, Hart ya no se reserva sus sarcásticas observaciones: la moral interna del Derecho está relacionada únicamente con la eficiencia del Derecho y tiene poco que ver con valores morales para ser, dice, la «moral del envenenamiento» (o con mayor precisión, la «eficiencia del envenenamiento») en el análisis de Hart. Si quieres envenenar a tu enemigo, «evita los venenos, pues aunque su forma, color o tamaño sean letales probablemente atraerán la noticia» ${ }^{28}$. La moral del Derecho consiste sólo en normas técnicas, propuestas al legislador: si quieres realizar un Derecho eficiente, entonces debes evitar utilizar normas penales retroactivas, expresiones imprecisas, reglas contradictorias, etc.

De acuerdo con Hart, Fuller confunde las dos nociones, una con otra: de un lado, el carácter final o intencional de las acciones humanas y los medios más efectivos para lograr una objetividad, y de otro, la moral de la práctica en cuestión. La insistencia de Fuller sobre la noción de propósito le ha cegado frente al hecho de que no es un problema qué tipo de acción humana intencional es la que se discute, que puede ser realizada a través de más o menos medios eficientes, pues los propios medios no tienen un valor inherente positivo o negativo. Los fines de la segregación racial o la violación de los valores básicos de la vida humana pueden ser perseguidos por los medios de la legalidad; también los fines de la vida buena y la persecución de la felicidad pueden ser alcanzados por medios no legales. Hart señala que no existe una conexión necesaria entre legalidad y fines aceptales de la vida humana, o entre la forma y el contenido del Derecho.

Con una sola excepción, Fuller analiza la moral interna del Derecho como reglas de la moral de aspiración y como tal está cercana, por ejemplo, a la idea de los principios jurídicos de Alexy. Sin embargo, Hart argumenta que al ver la moral interna del Derecho sólo como un aspecto de la labor del buen artífice del Derecho, Fuller tiene que aceptar también la idea de que el legislador que, por ejemplo, utiliza normas retroactivas de Derecho penal, sólo viola la moral de aspiración. De acuerdo con

${ }^{27}$ H. L. A. Hart, The Concept of Law, cit. pág. 202.

${ }^{28}$ H. L. A. Hart, Essays in Jurisprudence and Philosophy, cit. pág. 350. 
Hart esto es absurdo ${ }^{29}$. Sin embargo, si aplicamos el punto de vista de Hart a la misma cuestión, el resultado no es demasiado convincente. En la explicación de Hart el Derecho penal retroactivo se entendería como «mal» Derecho o finalmente como Derecho pero «demasiado inicuo para ser obedecido o aplicado» ${ }^{30}$. ¿En qué sentido la noción de Hart supera las dificultades planteadas por la moralidad de aspiración de Fuller y es juzgada como absurda por Hart? En mi opinión, ninguna. De hecho, el resultado final es bastante similar en los dos casos.

\section{LA TEORÍA DEL DERECHO Y LA MORAL DE ROBERT ALEXY}

\section{1. La «pretensión de corrección» y la conexión necesaria entre Derecho y moral}

El provocador artículo de Robert Alexy «On Necessary Relations between Law and Morality» aborda la verdadera cuestión que Hart y Fuller habían puesto de manifiesto, pero el marco conceptual de Alexy se desarrolla con posterioridad.

Alexy establece la distinción entre cuatro dicotomías individuales en la aproximación al Derecho: un concepto de Derecho que incluye y excluye la validez, norma y procedimiento, observador y participante y las conexiones definitorias y cualificatorias entre Derecho y moral ${ }^{31}$. Por otra parte, Alexy hace uso de la distinción entre una norma (o una decisión) y un sistema jurídico tomado en su conjunto. El esquema conceptual de Alexy es verdaderamente impresionante, y permite no menos de 64 combinaciones diferentes $^{32}$, pero sus formulaciones conceptuales no parecen avanzar demasiado respecto a su tesis principal. El propio Alexy elige referirse a las normas jurídicas válidas o a los sistemas jurídicos, de modo que el primer par de categorías se reduce a uno sólo. La distinción entre norma y procedimiento pone el acento en el objeto de estudio: el primero se refiere a los resultados finales o al producto de la creación normativa, mientras el último está referido a los procedimientos en sí mismos

${ }^{29}$ Ibid., págs. 350 y sigs.

${ }^{30}$ H. L. A. Hart, «Positivism and the Separation of Law and Morals», art. cit., pág. 56; The Concept of Law, cit. pág. 295.

${ }^{31}$ R. Alexy, «On Necessary Relations between Law and Morality», art. cit., págs. 171-172.

${ }^{32}$ Ibid., pág. 172. 
considerados. El punto de vista de un observador o de un participante del sistema jurídico en cuestión parece recordar la famosa distinción de Hart entre punto de vista externo e interno, tal como es formulada en The Concept of Law.

Con todo, la última dicotomía mencionada es la más interesante. Las conexiones definitorias de Alexy (entre Derecho y moral) definen una norma o un sistema jurídico como jurídico y una carencia a este respecto priva a la norma o al sistema de su validez jurídica. Por otro lado, las conexiones cualificatorias significan que si una norma jurídica o un sistema jurídico es defectuoso por razones conceptuales, no por ello carece de validez jurídica. En tal caso la norma jurídica o el sistema sólo son menos que perfecto, debido al defecto conceptual en él ${ }^{33}$. En la tesis de Alexy, la exigencia de corrección es de carácter definitorio con respecto al sistema jurídico tomado en su conjunto; mientras que en el caso de normas o decisiones individuales la conexión entre Derecho y moral sólo es de carácter cualificatorio. La pretensión de corrección establece el mencionado vínculo necesario entre Derecho y moralidad en la teoría de Alexy.

Sin embargo, la distinción entre una norma individual (o una decisión) y el sistema jurídico tomado en su conjunto puede producir algunos supuestos fronterizos. ¿Cómo deberíamos categorizar, señala Alexy, los artículos básicos de una constitución, cuyo primer artículo define la forma de gobierno?; ¿debería ser interpretado como una norma individual entre todas las demás o representaría el sistema jurídico globalmente considerado, su ideología jurídica inherente?

No obstante, una insistencia menor en la argumentación, la tesis principal de Alexy merece ser citada:

«La teoría de la pretensión afirma que las normas jurídicas individuales y las decisiones así como los sistemas jurídicos en conjunto tienen necesariamente una pretensión de corrección. Los sistemas jurídicos que no formulan explícita o implícitamente tal pretensión no son sistemas jurídicos. De modo que la teoría de la pretensión es de carácter definitorio. Los sistemas jurídicos que formulan dicha pretensión pero que no la satisfacen son sistemas jurídicamente defectuosos. A este respecto, la teoría de la pretensión es de carácter cualificatorio. La teoría de la pretensión juega un papel exclusivamente cualificatorio en el caso de normas y decisiones individuales. Son jurídicamente defectuosas si no hacen o no satisfacen la pretensión de corrección» ${ }^{34}$.

${ }^{33}$ Ibid., págs. 171-172, 178 y sigs., 181-182.

${ }^{34}$ Ibid., pág. 29. 
La idea de Alexy según la cual un defecto en la conexión definitoria priva al sistema jurídico de su validez jurídica mantiene un estrecho parecido con el pensamiento clásico de Aristóteles y Santo Tomás de Aquino. Su idea de la conexión cualificatoria entre Derecho y moral parece cercana a la noción de Fuller de la moral de aspiración que, según su propia terminología, afecta a la «perfección» de las normas jurídicas ${ }^{35}$ y a ser o no el resultado de «el orgullo de su artífice» ${ }^{36}$. Y, por supuesto, la moral de aspiración de Fuller mantiene un estrecho parecido con la noción de Alexy de los principios jurídicos, cuya realización, por definición, exige que sean optimizados. La pretensión de corrección establece la conexión necesaria entre Derecho y moralidad. De modo que una parte de la legislación que define la pretensión de conexión comete una contradicción performativa, al romper la conexión entre Derecho y moral.

\section{2. «Este es un Estado injusto»}

Alexy utiliza un ejemplo ficticio tomado del artículo primero de la constitución de un Estado recientemente establecido.

«X es un Estado soberano, federal e injusto» ${ }^{37}$.

De acuerdo con Alexy el artículo es, de alguna manera, defectuoso, y defectuoso no sólo meramente en sentido técnico, moral o convencional. Precisa que el artículo de la Constitución es conceptualmente defectuoso porque contiene una contradicción performativa, al violar la pretensión inherente al Derecho de corrección. ¿Cómo interpretar este tipo de ruptura de la conexión?

Si el artículo de la Constitución es tomado sólo como una norma jurídica entre todas las demás del sistema jurídico, tal defecto conceptual daría lugar a una ruptura de las conexiones cualificatorias entre Derecho y moral. Como tal el artículo produciría un «mal» Derecho o «menos que perfecto», según la terminología de Alexy. Y en este caso, el resultado final es bastante similar al análisis de Fuller, al añadir pocos argumentos nuevos al análisis de Fuller. Sin embargo, si el artículo de la Constitución en cuestión se toma como representativo de todo el sistema jurídico, pues formaría parte del esquema básico de toda la legis-

${ }^{35}$ L. L. Fuller, The Morality of Law, op. cit., pág. 41.

${ }^{36}$ Ibid., pág. 43.

${ }^{37}$ R. Alexy, «On Necessary Relations between Law and Morality», art. cit., pág. 178 y sigs. 
lación y jurisdicción del país, la cuestión cambia en una dirección más interesante. En este caso, un artículo de la Constitución tan injusto privaría a todo el sistema jurídico de su validez. Dado que el resultado final de la primera interpretación (es decir, el artículo de la Constitución como norma individual de un sistema jurídico) no ofrecería nuevos argumentos al debate clásico, presumo que Alexy persigue la última alternativa (esto es, la Constitución como lo más significativo del sistema jurídico en conjunto). Junto al supuesto «este es un Estado injusto», Alexy nos ofrece otro ejemplo extraído de una sentencia:

«El acusado es -injustamente, pues el Derecho válido fue interpretado incorrectamente- sentenciado a cadena perpetua $\rangle^{38}$.

Alexy formula la misma exigencia antes mencionada, afirmar que la decisión adolece de un defecto conceptual. «El juez comete una contradicción performativa y en este sentido un error conceptual. Una decisión judicial exige siempre aplicar el Derecho correctamente, no importa el grado de error que se dé. El contenido del veredicto contradice la pretensión hecha por el acto institucional de proclamar la sentencia» ${ }^{39}$.

\subsection{Sobre la contradicción performativa}

La tesis de la corrección de Alexy es provocadora. Supone que una contradicción performativa priva al sistema jurídico de su validez, pues las validez jurídica se basa en la pretensión de correción. Alexy se remite a la teoría del lenguaje de John L. Austin, al citar su famoso ejemplo de un enunciado autocontradictorio: «El gato está sobre el felpudo pero yo no lo creo ${ }^{40}$. ¿Es sostenible la tesis de Alexy? ${ }^{41}$

El ejemplo del gato sobre el felpudo de Austin es un enunciado constatativo que da información sobre el estado de cosas en el mundo. ¿La cuestión relativa a la verdad de los enunciados constatativos es perfectamente legítima y la respuesta es contin-

${ }^{38}$ Ibid., pág. 179.

${ }^{39}$ Ibid., pág. 180.

${ }^{40}$ Ibid., pág. 179.

${ }^{41}$ Agradezco mucho los comentarios formulados por Ernesto Garzón, Manuel Atienza, Ruth Zimmerling y Francisco Laporta en el simposium de Alicante. Especialmente Ernesto Garzón Valdés y Ruth Zimmerling defendieron las tesis de Alexy, mientras que Francisco Laporta y Manuel Atienza las consideraron incorrectas. Tras la fructífera discusión en Alicante volví a escribir parte de mi comunicación al simposium. 
gente con relación a si el estado de cosas enunciado realmente existe en el mundo? Es evidente que los enunciados autocontradictorios son lógicamente defectuosos y no pueden ser -verdaderos ni falsos- sino sin sentido. H. L. A. Hart una señaló que las «constituciones no crean dificultades por adoptar esta forma», refiriéndose a un tipo de artículo según el cual las leyes injustas o inmorales no tengan fuerza de obligar para los ciudadanos. Además de la posibilidad de «crear problemas», ¿qué más está en juego?

La teoría de Alexy se encuentra próxima a la idea de Habermas de pragmática universal. La concepción habermasiana afirma que los actos de habla pueden ser divididos en tres grupos, junto con sus características inherentes ${ }^{42}$ :

1) Enunciados constatativos: verdad.

2) Enunciados expresivos: sinceridad.

3) Enunciados regulativos: corrección.

El ejemplo de Alexy de un enunciado legislativo: «Este es un estado injusto», es un enunciado práctico (o regulativo) destinado a orientar la acción humana. De acuerdo con la fundamentación pragmático universal, bastante próxima a la teoría de Alexy, los enunciados tienen una pretensión de corrección.

Detengámonos en el tipo de artículo de la Constitución que Alexy utiliza en su ejemplo «este es un Estado injusto». Ciertamente viola la pretensión de corrección y el enunciado es, en palabras de Austin, efectivamente un enunciado «desafortunado». Pero -a diferencia de los enunciados constatativos- su exigencia lógica carece de sentido, debido a su no-corrección, cuando menos no es intuitivamente convincente. El legislador promulga una norma extraña sobre el carácter injusto del Estado ¿y qué? La validez formal del sistema jurídico difícilmente puede ser anulada por el extraño artículo en la Constitución y el sistema jurídico puede funcionar como cualquier sistema jurídico efectivo. Por consiguiente, me parece que la extrañeza de su validez formal y la analogía con el austiniano ejemplo del gato sobre el felpudo no funciona en el campo de los enunciados prácticos (regulativos), pues su status lógico es diferente de los enunciados constatativos.

Por lo que respecta al supuesto «esta es una decisión injusta», Alexy, por supuesto comprende que el juez comete un error jurídico. El veredicto, junto a la violación de la pretensión de corrección de Alexy, contradice abiertamente el Derecho. Dado

\footnotetext{
${ }^{42}$ J. Habermas, Theorie des Kommunikativen Handelns, cit., T. I., p. ej., pág. 443.
} 
que la pretensión de corrección está siendo violada, la conexión entre Derecho y moralidad queda rota. Sin embargo, el caso es diferente al ejemplo de Alexy: «este es un Estado injusto», pues lo que aquí está en juego no es la injusticia de un aspecto de la legislación sino una interpretación explícitamente contra legem. En la teoría de Alexy el veredicto contra legem no es, sin embargo, Derecho inválido, dado que una norma jurídica individual o una decisión no pueden ser sino «menos que perfecta» en razón del carácter cualificatorio de la relación entre Derecho y moral de este supuesto. Como he afirmado, sólo el sistema jurídico en su conjunto puede ser jurídicamente inválido por una ruptura del carácter definitorio de la relación entre Derecho y moral.

En otras palabras, la teoría de Alexy sólo afirma que un veredicto semejante: «Esta es una decisión injusta» constituye un aspecto erróneo de la jurisdicción. Ciertamente el fallo comprende un defecto conceptual, pero a la misma conclusión podría llegarse sin la formulación de la idea de contradicción performativa y de la pretensión inherente de corrección.

\section{TEORÍA DE ALEKSANDER PECZENIK SOBRE LA RELACIÓN ENTRE DERECHO Y MORAL ${ }^{43}$}

Aleksander Peczenik ha desarrollado una teoría muy interesante de la relación entre Derecho y moral ${ }^{44}$. Peczenik traza la distinción entre enunciados prácticos prima facie y enunciados prácticos all-things-considered. Las evaluaciones prima facie sólo tienen un carácter provisional, dado que otras consideraciones pueden modificar el resultado final consideradas-todas-las-circunstancias del procedimiento de evaluación moral. Las evaluaciones del tipo consideradas-todas-las-circunstancias tienen lugar a través del procedimiento de contrapeso y ponderación de los principios y valores implicados.

La tesis de la inclusión de Peczenik afirma que las obligaciones jurídicas tienen también un carácter moral.

«Si las leyes prima facie contienen, implican o de alguna otra forma, se basan explícitamente en la conclusión de que A tiene

${ }^{43}$ Estoy muy agradecido por los comentarios expuestos por Aleksander Peczenik y Aulis Aarnio en el simposium de Alicante.

${ }^{44}$ A. Peczenik, «Weighing Rights», Enlightenment, Rights and Revolution. Essays in Legal and Social Philosophy, N. MacCormick and Z. Bankowski, eds., op. cit., págs. 175-196. A. Peczenik, On Law and Reason, Kluwer Academic Publishers, Law \& Philosophy Library, vol. 8, 1989. 
cierto deber jurídico, pretensión, competencia o derecho puede sostenerse que A tiene un deber, pretensión, competencia o derecho moral prima facie, con el mismo contenido» ${ }^{45}$.

Me he centrado únicamente en la consideración de Peczenik de los deberes jurídicos, pues las modalidades jurídicas de Hohfeld pueden ser reducidas a dos de ellas, como ha hecho Hart, de hecho, en su The Concept of $L a w^{46}$, y la noción de deber (o la de n derecho) puede ser considerada como la más crucial de las modalidades jurídicas.

Como admite el propio Peczenik, incluso el sistema jurídico del régimen nazi establecería este tipo de deber moral prima facie. Un juez bajo el régimen nazi tendría un deber moral prima facie de hacer cumplir las disposiciones sobre los judíos. Sólo después del procedimiento de contrapeso y ponderación puede llegar a constatarse el carácter inmoral del Derecho nazi y puede perder su carácter moral prima facie $e^{47}$. No obstante, la situación es la misma con respecto a los argumentos consideradas-todas-las-circunstancias:

«Si una persona A tiene un deber jurídico, libertad, pretensión, etc., del tipo consideradas-todas-las-circunstancias, con respecto a una acción $\mathrm{H}$, entonces también tiene un deber, libertad, pretensión moral consideradas-todas-las-circunstancias del mismo contenido ${ }^{48}$.

Más adelante Peczenik argumenta que en el caso del Derecho nazi uno puede negar que se trate de un sistema jurídico por razones morales, pero en este caso la inmoralidad debe fundamentar sistemáticamente el sistema jurídico en su conjunto, incluidas las disposiciones técnicas del Derecho privado, etc. En este sentido sostiene que «no es suficiente una disposición inmoral o un aspecto sistemáticamente inmoral del sistema» ${ }^{49}$. También argumenta que un sistema jurídico válido no puede ser «demasiado inmoral» ${ }^{50}$. En otras palabras, Peczenik parece sostener una conexión entre Derecho y moral extremadamente fuerte incluso en el nivel consideradas-todas-las-circunstancias y sólo cuando el sistema jurídico llega a ser totalmente inmoral para los ciudadanos puede sostenerse que pierde su validez jurí-

${ }^{45}$ A. Peczenik, On Law and Reason, op. cit., pág. 242; «Weighing Rights», cit., pág. 177.

${ }^{46}$ Vid., L. L. Fuller, The Morality of Law, op. cit., pág. 134, nota núm. 50.

${ }^{47}$ A. Peczenik, On Law and Reason, op. cit., pág. 243; «Weighing Rights», cit., págs. 177-178.

${ }^{48}$ Ibid., pág. 243; ibid., pág. 181.

${ }^{49}$ Ibid., pág. 243; ibid., pág. 178.

${ }^{50}$ A. Peczenik, «Weighing Rigths», cit., pág. 188. 
dica. En el caso de una disposición jurídica inmoral se podría -y se debería- interpretarla de un modo restrictivo o se podría ignorar la disposición junto con el procedimiento jurídico de contrapeso y ponderación ${ }^{51}$.

Sin embargo, la exigencia que formula Peczenik respecto a la inmoralidad total de un sistema jurídico puede suponer una condición demasiado estricta para el régimen nazi, dado que exige que incluso una parte meramente técnica del sistema jurídico deba ser inmoral en orden a que el sistema jurídico sea privado de su validez. Y este supuesto no se dio siquiera en el régimen nazi, aun cuando hubiera aspectos de la legislación extremadamente inhumanos con respecto a los judíos y a otras razas «inferiores». La promulgación por ejemplo del BGB (Bürgerliches Gesetzbuch, el código civil alemán) permaneció inalterada durante mucho tiempo. Y, de hecho, el propio Peczenik hace uso de un ejemplo del Derecho nazi en su argumentación ${ }^{52}$.

¿Cuáles son los argumentos de Peczenik en favor de una tesis fuerte de la relación entre Derecho y moral? Peczenik argumenta que «al introducir la institucionalización del orden jurídico, la sociedad puede restringir, aunque no eliminar enteramente, la necesidad del procedimiento de contrapeso y ponderación ${ }^{53}$. Más adelante prosigue:

«Si una sociedad moderna no tuviera un ordenamiento jurídico, se produciría un caos moralmente cuestionable. De este modo es mejor desde el punto de vista moral tener una sociedad que posea un ordenamiento jurídico que en algunos casos lleve a decisiones injustas que obligar a las personas individuales a estar sujetos a sus propios juicios morales en todos los casos ${ }^{54}$.

Peczenik parece hacer uso de la teoría de la naturaleza humana de Thomas Hobbes y a la explicación hobbesiana de la condición humana en el «estado de naturaleza», es decir, sin la existencia del poder coercitivo del Estado. Por mi parte, encuentro la noción de naturaleza humana de Hobbes bastante realista y de este modo puede ser defendido el punto de partida de Peczenik. Hobbes también subraya la necesidad de una interpretación de autoridad por parte del soberano en las situaciones conflictivas de los ciudadanos y esta concepción parece encajar bien con la idea de Derecho que presenta Peczenik. Sin embargo, la

${ }^{51}$ A. Peczenk, On Law and Reason, op. cit., pág. 254; «Weighing Rights», cit. pág. 182.

${ }^{52}$ Vid., por ejemplo, A. Peczenik, On Law and Reason, op. cit., pág. 243.

${ }^{53}$ Ibid., pág. 178.

${ }^{54}$ Ibid., págs. 179-180. 
noción de Peczenik según la cual un deber jurídico del tipo consideradas-todas-las-circunstancias implica un deber moral consideradas-todas-las-circunstancias, parece propiciar la crítica. De acuerdo con este autor, el procedimiento interpretativo de contrapeso y ponderación o comprende también, por definición, valores morales ${ }^{55}$. Es por ello que los valores morales siempre están presentes en el resultado final de la interpretación, la tesis de la inclusión de Peczenik no es más que un enunciado analítico, cuya verdad se sigue de la mera definición del concepto de interpretación jurídica. Pero, ¿de qué moralidad está necesitada la interpretación para decidir un caso difícil dado? ¿Un juez bajo el régimen nazi no debería utilizar en la interpretación jurídica los principios adoptados por el sistema jurídico nazi, por ejemplo, aquellos basados en el status racial del caso implicado? Las reglas de Alexy de la racionalidad-D, que Peczenik utiliza en su libro, son meramente de carácter formal e impropias para orientar al juez en su dilema moral.

(Trad. de María José Añón)

${ }^{55}$ Vid., por ejemplo, A. Peczenik, On Law and Reason, op. cit., pág. 34: «Si las decisiones en un supuesto dado se adoptan sin atención a la tradición del razonamiento jurídico establecida, éstas no son jurídicas, por definición. Si se adoptan sin atención a consideraciones morales, tampoco son jurídicas, por definición.» 